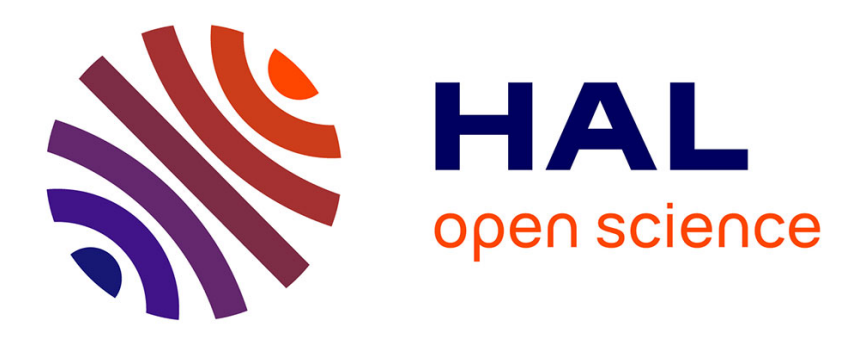

\title{
Self-organization and interareal networks in the primate cortex.
}

Henry Kennedy, Colette Dehay

\section{To cite this version:}

Henry Kennedy, Colette Dehay. Self-organization and interareal networks in the primate cortex.. Prog Brain Res, 2012, 195, pp.341-60. 10.1016/B978-0-444-53860-4.00016-7 . hal-00663248

\section{HAL Id: hal-00663248 \\ https://hal.science/hal-00663248}

Submitted on 26 Jan 2012

HAL is a multi-disciplinary open access archive for the deposit and dissemination of scientific research documents, whether they are published or not. The documents may come from teaching and research institutions in France or abroad, or from public or private research centers.
L'archive ouverte pluridisciplinaire HAL, est destinée au dépôt et à la diffusion de documents scientifiques de niveau recherche, publiés ou non, émanant des établissements d'enseignement et de recherche français ou étrangers, des laboratoires publics ou privés. 


\title{
Self-organization and interareal networks in the primate cortex
}

\author{
Henry Kennedy and Colette Dehay
}

(1) Stem cell and Brain Research Institute, INSERM U846, 18 Avenue Doyen Lepine, 69500 Bron, France. (2) Université de Lyon, Université Lyon I, 69003, Lyon, France

\begin{abstract}
Variability of gene expression of cortical precursors may partially reflect the operation of the gene regulatory network and determines the boundaries of the state space within which self-organization of the cortex can unfold. In primates, including humans, the outer subventricular zone (OSVZ), a primate-specific germinal zone, generates a large contingent of the projection neurons participating in the interareal network. The number of projection neurons in individual pathways largely determines the network properties as well as the hierarchical organization of the cortex. Mathematical modeling of cell-cycle kinetics of cortical precursors in the germinal zones reveals how multiple control loops ensure the generation of precise numbers of different categories of projection neurons and allow partial simulation of cortical self-organization. We show that molecular manipulation of the cell-cycle of cortical precursors shifts the trajectory of the cortical precursor within its state space, increases the diversity in the cortical lineage tree and explores changes in phylogenetic complexity. These results explore how self-organization underlies the complexity of the cortex and suggest evolutionary mechanisms.
\end{abstract}

Keywords: corticogenesis-development-neocortex-macaque-monkey-connections-pathways-proliferation-cell cycle-outer subventricular zone-evolution

\section{Introduction}

Under non-equilibrium conditions, natural occurring fluctuations amongst the multiple components of an emerging complex system may undergo reorganization towards a dynamic equilibrium. Under dissipative conditions with a maintained energy input, dynamic equilibrium allows complex spatio-temporal patterning and the system is said to self-organize. Self-organization underlies the complexity found in both the biological and non-biological world and therefore is expected to play a decisive role in the development of the cerebral cortex (Halley and Winkler, 2008a).

In biocomplex systems it is not evident what is meant by the natural occurring fluctuations that will be finely tuned by the self-organization process. Recent work in stem cell biology goes some way to suggesting what could be the initial conditions that support self-organization. A population of stem cells derived from a single cell were shown to exhibit a bell-shaped curve of protein expression (Chang et al., 2008). Flow cytometry analysis shows that the observed wide dispersion of protein levels is due to slow fluctuations over days of gene expression and may contribute to stemness. While phenotypic variability may specifically contribute to stem cell biology, it also may have profound implications for understanding cell fate and diversity. Understanding the origins of this non-genetic phenotypic heterogenity can best be approached in the framework of the epigenetic landscape (Huang, 2009).

Waddington coined the term epigenetic landscape that has been interpreted by Stewart Kaufmann as an attractor landscape in the high-dimensional genome-wide gene expression state space (Kauffman, 1993) Figure 1. The landscape topography reflects the substructure of the state space where each point $S(t)$ represents a network state of the gene regulatory network, reflecting the collective expression of the genome via the activity states of the $\mathrm{N}$ genes $X_{i}$,

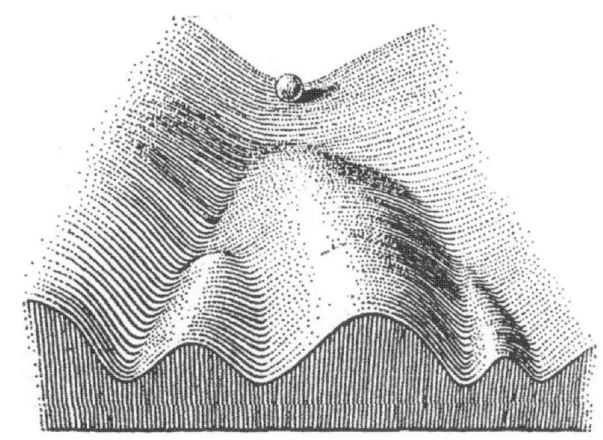

Figure 1. The Epigenetic landscape of Waddington 
$S(t)=\left[x_{l}(t), x_{2}(t), \ldots x_{N}(t)\right]$

Conflicting network interactions mean that some configurations of gene activity $\mathrm{S}(\mathrm{t})$ are more stable and constitute valleys while others are unstable (hill tops) (Fig. 1). Kauffman proposed that the valleys are attractors states and correspond to a distinct subclass of model gene networks defining cell types. These basins of attraction drain the slopes in their neighborhood, and the collection of valleys and hilltops constitutes an Ndimensional space, which is explored by the dynamics of the gene regulatory network (Brazhnik et al., 2002).

There are a number of different approaches one can adopt to study cortical development. One is to describe the cellular events, usually in vitro, of various developmental stages. This approach is often coupled to the study of gene expression and ultimately with the modification of the expression of one or more genes. While this molecular level of investigation is extremely powerful, there are numerous occasions where the removal or over expression of a gene will have little effect on the developmental process where the gene is expressed, thereby testifying on the one hand to the complexity of the developmental process, and on the other indicting the limitations of the reductionist approach. An alternative but complementary approach is to record events during development in such a way as to be able to develop a quantitative database sufficiently detailed to allow a simulation of the developmental process itself (Zubler and Douglas, 2009; van Ooyen, 2011). This requires adopting an experimental methodology that makes it possible to obtain reliable count data. This provides a valuable means of testing the cellular mechanisms and relevant molecular data but more importantly to link specific aspects of the developmental process to key functional features of the mature cortex. But above all, simulating development can provide insight into the integration of the multiple interactions of diverse components and therefore provide a deeper understanding of the complexity of the cortex (van Ooyen, 2011).

Here we set out to review processes that may underlie the self-organization of the cortex. This involves briefly describing the complexity of cortical function before proceeding to identify essential aspects of the architecture supporting this function. We describe a number of developmental studies that outline the regulatory control of cortical projection neuron production, and how this regulatory control acts on the phenotypic variability of cortical stem cells.

\section{Self-organization in ontogeny, phylogeny and the role of postnatal experience}

The cortex detects statistical regularities in the environment by sensing local and global correlations of neuronal activity. In this way, invariant characteristics of the world can be inferred as illustrated by color constancy and object segmentation. This notion of cortical function tempers efforts to understand the brain uniquely by studying all of its component independently of the environment, and is relevant in a deep sense to understanding both the development and function of the cortex. It suggests that for understanding function, it is necessary to consider the statistical features of the environment that the brain is able to detect, and to directly link the structural/functional properties of the brain to its perceptual capacities (Shepard, 2001). For understanding development, detection of the statistical features is expected to largely depend on selforganization (Kennedy and Dehay, 1993). This is upheld by recent evidence that shows that during cortical development there is a progressive optimization of the internal model of area V1 to the statistics of the natural visual environment that is achieved by adjusting the weights of connections (Berkes et al., 2011).

To understand self-organization we need to take into account the environmental factors that have molded its phylogenetic history. This suggests that self-organization and natural selection are two facets of the single evolutionary process (Kauffman, 2000; Halley and Winkler, 2008b). The self-organization process means that corticogenesis cannot be understood uniquely in terms of molecular pre-specification, but must also take into account the internal and external environmental factors that modulate organization as cortical development unfolds.

The developing sensory apparatus produces environmental information from which the brain needs to extract behaviorally relevant patterns. By rewiring or re-weighting connections, it tunes itself to or learns about coherent (and presumably relevant) patterns in its input. This unsupervised classification procedure is used to generate self-organized maps. There is evidence that the neuronal mechanisms of ontogenetic self-organization actually persist into adulthood when they mediate adaptive changes in learning and memory.

The species as a whole is subject to environmental patterns that exert pressure through natural selection that could promote the development of suitable circuits and processing modules, that are tuned to the exigencies that led to survival of the current generation (Geisler and Diehl, 2002). The proposed process carries the prediction that corticogenesis even at very early stages of development is influenced by extrinsic factors, echoing earlier stages of phylogeny. During the early 1970's there were considerable efforts to show that corticogenesis is significantly shaped by extrinsic factors related to the sensory periphery (Van der Loos, 1977). This work was largely supported by the observation that visual experience plays an important role in the elaboration of the functional architecture of the primary visual cortex (LeVay et al., 1980; Thompson et al., 1983). This 
understanding of corticogenesis, was later referred to as protocortex theory but has been largely superseded by protomap theory which postulates that corticogenesis is driven by intrinsic molecular mechanisms. While in recent years there has been overwhelming evidence in favour of a genetic specification of cortical areas, this evidence does not invalidate the numerous instances of so called afferent specification of the cortex and points to the need for a reappraisal of self-organization (O'Leary, 1989; Killackey, 1990; Kennedy and Dehay, 1993; Sur and Rubenstein, 2005).

Because self-organising biological systems are initially in a poorly differentiated state and by definition respond over time to changing signals from the environment one might expect that they would be characterized by prolonged maturational processes in relation to their complexity. The phenomena of self-organization has been traditionally linked to Hebbian plasticity by which competitive modification of synaptic strength underlies experience-dependent self-organization of the functional properties of the visual cortex, so leading to postnatal plasticity in the orientation and ocular dominance domains as well as the analysis of visual movement (LeVay et al., 1980; Kennedy and Orban, 1983; Thompson et al., 1983).

\section{Self-organization and the OSVZ-SGL model}

Compared to the other species, the primate cortex is characterized by an overrepresented supragranular layer (SGL) compartment whose neurons are dedicated to forming local connections as well as the transfer of information between cortical areas (Fig. 2). In monkey cortex, the SGL is generated by a primate-specific germinal zone during in utero development. Later postnatally there is a remodelling of the connectivity of the SGL when the animal is visually exploring its environment (Kennedy et al., 1989; Barone et al., 1995; Barone et al., 1996). A further argument in favor of self-organization in the SGL is a dependency on activity for correct development. This has been shown to be the case for cortico-cortical pathways since immature cortical pathways are highly susceptible to manipulation of the ascending pathways (Dehay et al., 1986; Dehay et al., 1989). In the present review we shall examine the possibility that environmental factors might contribute to shaping the function of these cortical layers and that this might be a characteristic feature of primate cortical development.
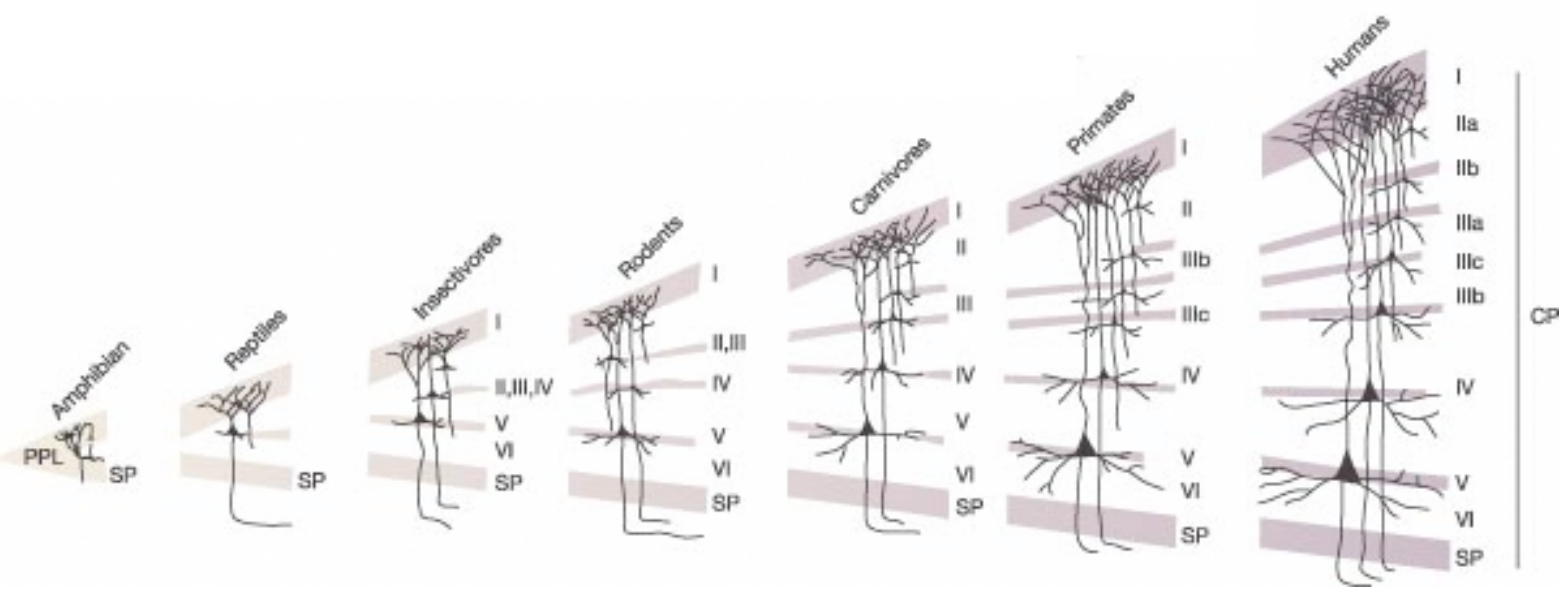

Figure 2. Evolution of the supragranular layers of the cortex. Supragranular layers (SGL), generated late in neurogenesis, are greatly expanded in the primate cerebral cortex, especially in humans. In primates SGL neurons form local patchy connections and feedforward long distance cortico-cortical connections. (Reprinted with permission from Hill and Walsh, 2005).

In the six-layered cortex, the supragranular layers are dedicated to forming inter-areal connections in contrast to the infra-granular layers, which contain projection neurons that project to subcortical structures as well as to cortical areas. It is generally accepted that the physiological function of the cortex is shaped by the pattern of interareal connections. Here we shall focus on the supragranular layers of the cortex that are thought to undergo selective expansion in primates (Dehay and Kennedy, 2007). In a first instance we shall review how connection weight determines the general network and hierarchical features of the cortical network. We will then show how the stringent control of the proliferative program of the cortical progenitors in the germinal zone determines the exact numbers of the different projection neurons that constitute the cortical network. Because the control of cortical precursors comes under multiple environmental influences and determines the structural features of the cortex it is best understood in the context of self-organization.

The pyramidal projection neurons of the neocortex are generated by at least 5 different progenitor cell types located in the germinal zones lining the ventricle. The first progenitors in the cortex are the neuroepithelial cells (NECs), which give rise to radial glial progenitors (RGPs), the grandmother cell of cortical development as they give rise directly or indirectly to all cortical projection neurons (Heins et al., 2002; Malatesta et al., 2003). 
Both NECs and RGPs divide at the apical surface and form the ventricular zone, which is the first formed germinal zone. Iain Smart observed, as far back as 1973, that relatively early on crowding of precursors due to queuing at the apical surface is relieved by some precursors shifting to undergo mitosis at the top of the ventricular zone (Smart, 1973). These basal dividing precursors were referred to as intermediate progenitors (IP), shown to express the transcription factor Tbr2 which distinguished them from the NECs and RGPs, which express prominin 1 and the transcription factor Pax6 (Götz et al., 1998; Malatesta et al., 2000; Hartfuss et al., 2001; Miyata et al., 2004; Noctor et al., 2004). Finally a short neural precursor (SNP) was identified in the early ventricular zone, which like the RGPs undergoes apical or near apical division (Gal et al., 2006).

A major research breakthrough occurred when it was shown that the RGPs are not only part of a glial scaffolding, but also constitute multipotent cortical progenitors (Malatesta et al., 2000; Noctor et al., 2001; Noctor et al., 2002). There is further heterogeneity of RGP in the embryonic primate, where a fraction cease dividing and function as migration scaffolding for several months before reinitiating proliferation and generating astrocytes (Schmechel and Rakic, 1979; Rakic, 2003).

There is a major difference in the cellular composition of the primate outer subventricular zone OSVZ with respect to the rodent SVZ. Whereas in the rodent all RGP nuclei are restricted to the VZ, RGPs somata are morphologically identified in the OSVZ of the primate (Fietz et al., 2010; Fish et al., 2008; Hansen et al., 2010; Levitt et al., 1981; Lukaszewicz et al., 2005). There is evidence that precursors of the primate OSVZ express Pax6, which characterizes RGP identity in the rodent (Fish et al., 2008).

A number of observations link production of infragranular layers to VZ and SVZ to production of SGL. Although SVZ are derived from VZ precursors, there are clear differences in gene expression between the two precursor pools and these differences correlate with distinct neuronal progeny. For instance, Otx 1 and Fez1 are both expressed in VZ precursors and down regulated in SVZ and then subsequently upregulated in subsets of deep-layer neurons (Frantz et al., 1994; Arlotta et al., 2005; Chen et al., 2005a; Chen et al., 2005b; Molyneaux et al., 2005). Furthemore, both Otx1 and Fez1 play a crucial role in specifying the axonal projections of subsets of lower layer neurons. Recent studies in mice show that several transcription factors (Cux2, Tbr2, Satb2, and Nex) (Nieto et al., 2004; Zimmer et al., 2004; Britanova et al., 2005; Wu et al., 2005; Pinto et al., 2009), as well as the non-coding RNA Svet-1 (Tarabykin et al., 2001) are selectively expressed in both the SVZ and in upper layer neurons. This congruency of expression of genes first in SVZ progenitors and subsequently in supragranular neurons together with time-lapse microscopy observations suggest that the SVZ gives rise to upper layer neurons (Tarabykin et al., 2001; Noctor et al., 2004; Zimmer et al., 2004).

Consistent with these findings, distinct molecular mechanisms have been identified for the specification of infra- and supragranular neuronal lineages. Studies from mutant mice show that Ngn1 and Ngn2 activity are required for the specification of a subset of infragranular neurons but not for the specification of SGL neurons. In contrast, Pax 6 and Tlx, two genes required for the formation of the SVZ (Nieto et al., 2004; Roy et al., 2004; Zimmer et al., 2004), are synergistically involved in the specification of SGL (Schuurmans et al., 2004). It therefore can be hypothesized that the selective expansion of the SGL compartment in the primate cortex results from modifications of the Pax6/Tlx related specification without modification of the Ngn specification mechanisms (Schuurmans et al., 2004).

In apparent contrast to the above mentioned links between the SVZ and the SGL is the observation that in rodent the IPs contribute neurons to all cortical layers (Haubensak et al., 2004; Miyata et al., 2004; Noctor et al., 2004; Shen et al., 2006; Kowalczyk et al., 2009). This has led to the suggestion that rodent IPs are universal generators of neurons, and in this sense the separation of the germinal zones in to $\mathrm{VZ}$ and SVZ might be considered arbitrary, and instead we should distinguish between apical (NECs and RGPs) and basal dividing progenitors (IPs). However, while there is overwhelming evidence that IPs contribute neurons to all cortical layers there is also evidence that IPs in the VZ and SVZ display important differences. Tbr2+ IP-like progenitors undergo apical or subapical mitosis and constitute as much as $5-20 \%$ of the total Tbr2+ population (Kowalczyk et al., 2009) and are reported to resemble the short radial SNPs (Gal et al., 2006). The distinction between rodent IPs in the VZ and SVZ is supported by the following. Firstly, whereas the IPs in the VZ have radial morphologies, those in the SVZ and the interface between SVZ and VZ have multipolar morphologies as first described in 1973 by Smart (Smart, 1973; Kowalczyk et al., 2009). Secondly, while time lapse observations suggest that IPs undergo only 1 or 2 proliferative divisions, their could be a difference in the tendency of IPs in the SVZ to undergo more frequent proliferative divisions given the decrease of the neurogenic fraction in basal divisions during corticogenesis (Kowalczyk et al., 2009). Further investigations are needed to determine if the different categories of IP cells have distinct cell cycle kinetics (Arai et al., 2011). If this should be the case this would further the distinction of IPs in the VZ and SVZ. Under these circumstances the fact that IPs contribute neurons to all layers fails to invalidate the observed links between SVZ and SGL. In the primate visual cortex, more than $75 \%$ of cortical neurons destined for the upper layers originate from SVZ precursors (Lukaszewicz et al., 2005). 
In the primate there is an important elaboration of the SVZ to form an imposing outer component (OSVZ) which is not observed in the rodent (Smart et al., 2002) (Fig. 3). The OSVZ is a distinct histological structure that is bounded by two clearly defined fiber pathways (the outer and inner fiber layers) that have no parallel in the developing rodent or carnivore. The homologous structure of the rodent SVZ in the primate could be the ISVZ, which like the rodent SVZ is in contact with the VZ. The OSVZ exhibits a number of unique features. Contrarily to what is observed in the rodent, where the VZ is the major germinal compartment throughout corticogenesis, the primate VZ declines rapidly during the course of corticogenesis. This decline is associated with an early appearance of the SVZ followed by the OSVZ. This primate-specific organization, first described in the monkey (Smart et al., 2002), has also been subsequently observed in the developing human cortex (Fietz et al., 2010; Hansen et al., 2010; Zecevic et al., 2005).
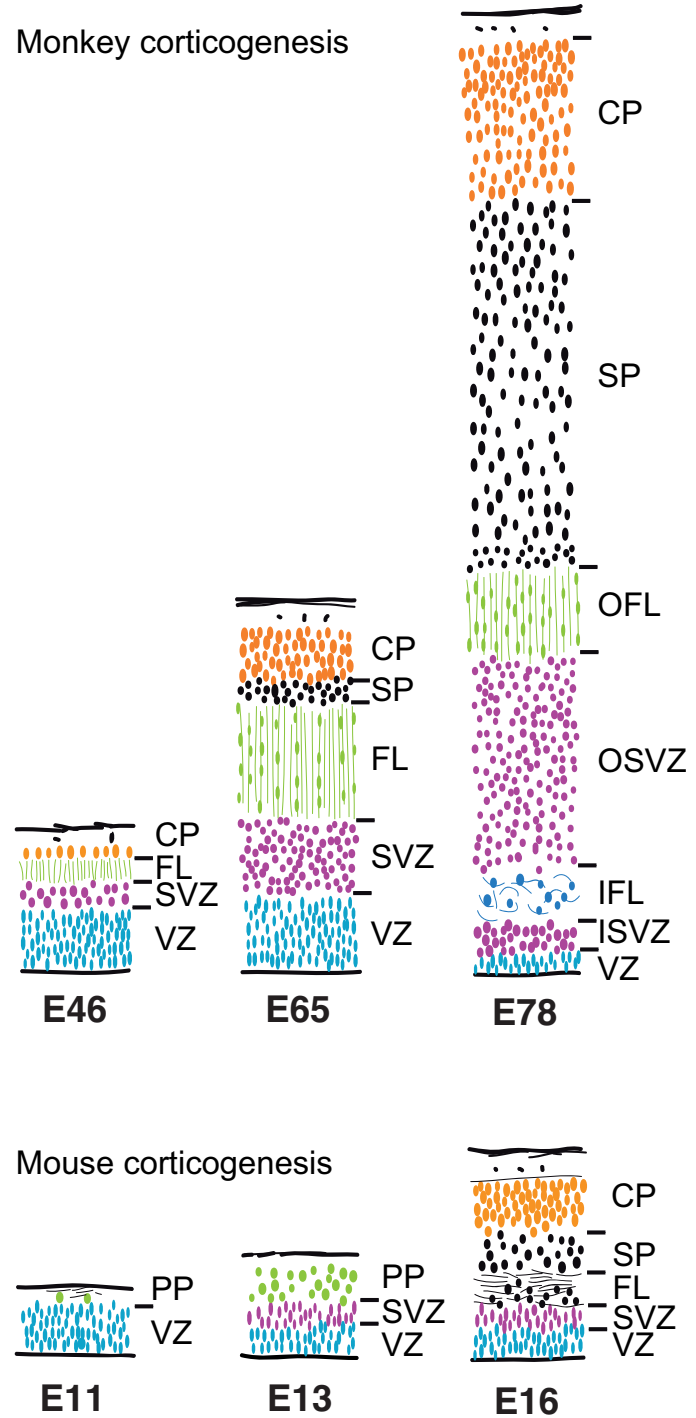

Figure 3. Comparison of human and mouse germinal zones at equivalent developmental stages. These drawings are transects through presumptive Area 17 in monkey and mouse dorsal cortex at comparable developmental stages. The depth of each layer is drawn to a common scale. In the primate, an early appearing outer fibre layer (OFL) forms a major landmark. The ventricular zone (VZ) declines progressively after E65. The subventricular zone, by contrast, increases progressively in depth and by E72 is divided into an inner subventricular zone (ISVZ) and outer subventricular zone (OSVZ) by an intruding inner fibre layer (IFL). The increase in the OSVZ is particularly important between E65 and E72 and occurs as the VZ declines. CP cortical plate; SP subplate (adapted from Smart et al., 2002).

Enlargement of the SVZ precursor pool in the primate might correspond to an evolutionary adaptive mechanism ensuring the increased neuronal output necessary to build a more highly developed neocortex involving a pronounced cytological complexification of the SGL (Dehay et al., 1993; Smart et al., 2002; Lukaszewicz et al., 2005). The rodent SVZ is only partially self-sustaining and instead has to receive a constant supply of precursors from the VZ (Reznikov et al., 1997; Haubensak et al., 2004; Miyata et al., 2004; Noctor et al., 2004; Wu et al., 2005). In primates self-renewal (i.e. precursor divisions leading to an increase in numbers of 
precursors) would appear to be much more pronounced in the OSVZ than in rodent SVZ (Smart et al., 2002; Lukaszewicz et al., 2005).

The determination of neuron numbers composing either a cortical area or a cortical layer has been shown by a technique, referred to as the mitotic history of the neuron (Dehay and Kennedy, 2007), to crucially depend on the modulation of the mode of division where high rates of proliferative division lead to increases in the production of neurons (Polleux et al., 1997; Polleux et al., 1998). Because cytoarchitecture is characterized by differences in the numbers of neurons in individual layers, arealization and lamination are two sides of the same coin. Hence the spatial and temporal modulation of the frequency of proliferative divisions of cortical precursors determine the cytoarchitecture of the cortex (Dehay and Kennedy, 2007).

While the improved understanding of the IP precursor does not invalidate the suggested links between SVZ and SGL referred to above, it does give an improved conceptual framework for understanding the organizational principles underlying corticogenesis, as postulated by Hevner and his co-workers (Pontious et al., 2008). These authors have identified three competing but in our view not mutually exclusive hypotheses: the upper layer hypothesis (ULH), the intermediate progenitor hypothesis (IPH) and the radial amplification hypothesis (RAH).

The ULH points to the evidence linking SVZ and SGL (Tarabykin et al., 2001; Nieto et al., 2004; Zimmer et al., 2004; Britanova et al., 2005) and argues that a distinct population of IPs generate the SGL. Further, it is postulated that the population of IPs in question reside in the SVZ. The major objection of the Hevner group against the ULH is that IPs have been shown to contribute to all cortical layers (Pontious et al., 2008), however as we argue above there are reasonable grounds to suggest that IPs in the VZ and SVZ may constitute distinct precursor types and in any case the ULH remains an accurate description of the correlations between SVZ morphogenesis, gene expression and the production of the upper layer neurons during middle to late stages of corticogenesis (Pontious et al., 2008). As discussed above modulation of mode of division of cortical precursors has been implicated in determining cytoarchitecture via specifying the laminar thickness and hence arealisation (Dehay and Kennedy, 2007). Because IP is the major precursor involved in amplification of neuron number these findings implicate a special role of the IP both in determining laminar thickness and areal extent of cortex and this is what Pontious et al., referred to as the IP-hypothesis (Pontious et al., 2008). The increased expansion of the occipital pole of the fetal monkey is thought to be related to the extensive size of the OSVZ in this region and this suggests a link between gyrification and IPs (Smart et al., 2002; Lukaszewicz et al., 2006), which has been further elucidated in the ferret (Kriegstein et al., 2006; Martinez-Cerdeno et al., 2006). Because IPs respond to extrinsic signals released by the thalamic fibers (Dehay et al., 2001) and to genes that control specification of areas and growth (Land and Monaghan, 2003; Roy et al., 2004; Schuurmans et al., 2004; Yun et al., 2004; Bedford et al., 2005; Cappello et al., 2006; Chen et al., 2006; Zhou et al., 2006; Holm et al., 2007; Quinn et al., 2007), IPH postulates that IP amplification determines the arealization both during development and evolution (Molnar et al., 2006; Cheung et al., 2007).

The lack of evidence for IPs amplification in mice influencing expansion of cortical surface area is the major argument put forward by Pontious and colleagues (Pontious et al., 2008) in favor of the RAH. In contrast to IPs, factors influencing RGPs have been shown to influence cortical surface area (Kuida et al., 1998; Chenn and Walsh, 2002; Hevner, 2005; Inglis-Broadgate et al., 2005). However, the objection that changes in abundance of IPs cannot impact on surface area ignores two important findings. Firstly, removal of thalamic input to the cortex via bilateral in utero enucleation drastically reduces the dimensions of cortical area 17 (Rakic, 1988; Dehay et al., 1989, 1991). Because the removal of inputs to the cortex occurred after the early phase of expansion of the RGPs it would seem to be a direct consequence of alteration of the proliferation of IPs. This would seem to argue against IPH and in favor of RAH. However, this understanding of the RAH is based on the erroneous notion that RGPs undergo early symmetrical division to establish the pool of RGPs prior to the onset of neuron production. In fact it is now established that RGPs proliferation occurs continuously throughout corticogenesis (Miyata et al., 2004; Noctor et al., 2004; Kowalczyk et al., 2009). Hence, factors that influence IPs could also be influencing RGPs either directly or indirectly. That such influences might exist is illustrated in recent experiments aimed at accelerating the cell-cycle by selective reduction of G1 via transfection of cyclin $\mathrm{E}$ in rodents (Pilaz et al., 2009). The cell cycle acceleration of Pilaz et al., 2009 confirmed the hypothesis of the control of mode of division by cell cycle duration (Dehay et al., 2001; Lukaszewicz et al., 2002; Calegari and Huttner, 2003; Gotz and Huttner, 2005; Lukaszewicz et al., 2005).

The cell cycle acceleration study of Pilaz et al., 2009 was carried out in mouse and showed that reduction of G1 led to an increase in the frequency of proliferative divisions where both daughter cells re-enter the cell cycle accompanied by a decrease in differentiative neurogenic divisions where daughter cells quit the cell cycle to become neurons. This cell cycle re-entry led to a transient expansion of the precursor pool followed by a subsequent surge in neuron production. Interestingly, the increase in cell cycle reentry of the Pax6+ RGPs was very short lived and did not appear to have any consequence on the dimensions of the RGPs pool nor the 
cortex. This contrasted with the effects of cell cycle acceleration on the Tbr2+ population, which showed a much bigger amplification leading to a marked and relatively long-lived increase in the dimensions of the SVZ followed by an increase in the production of SGL neurons and the thickness of the supragranular layers. This "primatization" of the rodent cortex via a selective increase in the SVZ coupled with an expansion of the SGL suggests a conceptual exploration of the IPH and the RUH. Cell cycle acceleration experiments by Calegari's group revealed a 300\% increase in cortical surface area (Lange et al., 2009), which could suggests that the increased IP population has a feedback control on proliferation in the RGPs population; which causes the increase in cortical size. Certainly such an influence of the IPs on the RGPs is required to explain the claims of the role of IPs in gyrification (Smart et al., 2002; Kriegstein et al., 2006; Lukaszewicz et al., 2006; MartinezCerdeno et al., 2006). For instance in the E80 fetal monkey at the onset of SGL production there is a very prominent OSVZ which decreases in size concomitantly with the increased rates of neuron production and the very rapid growth of the occipital pole and the formation of the lunate sulcus. During this period of ballooning out of the occipital pole the cortical plate of the incipient area 17 is actually thinner then the presumptive area 18 despite the fact that later in the adult it will house a greater number of neurons in its thickness (Lukaszewicz et al., 2006). During this period of rapid occipital pole growth the maintenance of the VZ will require an increase in rates of proliferation and implies that there is a concerted mitogenic effect relayed from the OSVZ down to the VZ.

\section{Neuron number specifies cortical networks}

The study of complex networks has had an important impact on a wide range of scientific fields including social sciences, physics and biology. In fact any situation involving the interaction of numerous components to form complex systems with emergent properties can be investigated usefully with a graph theoretic approach. In this way understanding connectivity has made important contributions to phenomena as diverse as molecular interactions, metabolic pathways, ecological food webs and the brain (Sporns, 2011).

A number of studies have applied graph theory to investigate the network of connections linking cortical areas. A number of studies have used the data base of Felleman and Van Essen based on the compilation of data across some 350 papers concerning the connectivity of 31 cortical areas (Felleman and Van Essen, 1991). Malcolm Young and his colleagues used multidimensional scaling in order to obtain a topological model of the cortex (Young, 1992). Jouve used a similar approach modified in such a way as to infer connections that had not been tested (Jouve et al., 1998). This showed that the frontal eye field, a prefrontal area involved in directing attention, had a surprisingly central position in the cortical graph (Fig. 4).

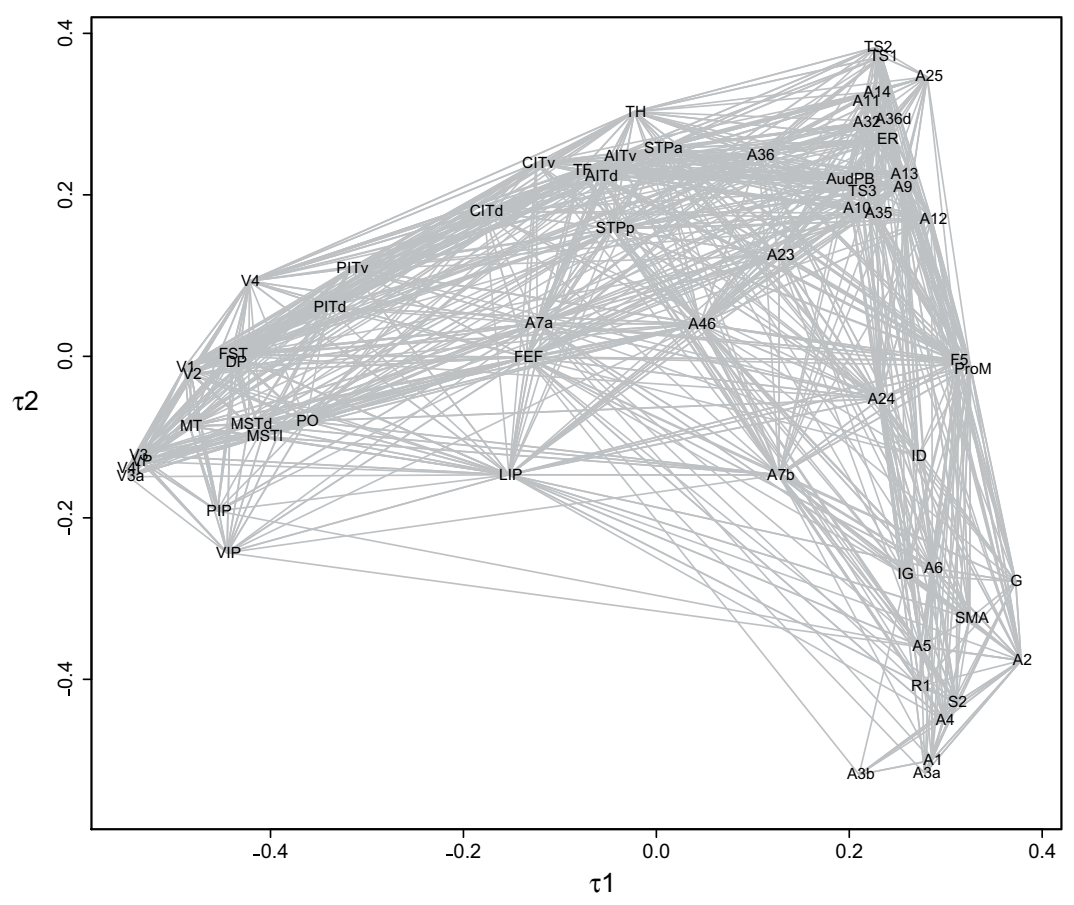

Figure 4 Topological model of cortex. Using Jouve's algorithm (Jouve et al., 1998) on a data base of Barone (Barone et al., 2000). The network organization of the cortex can be represented as a graph, where cortical areas are nodes and the pathways between areas are the links between nodes. In this model, areas are closer according to the similarity of their connectivity. 
Studies using a data base which has been compiled from the published literature suffer from the presence of numerous connections that have not been tested. To overcome this we have carried out an exhaustive study of the inputs to 26 cortical areas (Markov et al., 2011a). This enables us to determine the percentage of connections that exist in comparison to the theoretical maximum connectivity. This is referred to as the density of the graph. Network studies using previous published data base have chosen to ignore the untested connections and this has led them to conclude that the density of the graph is between 12 to $30 \%$ (Honey et al., 2007).

In our study we found that the density was considerably higher, in the region of 60 to $70 \%$. At such high densities the binary (ie connected/not connected) features of the graph reveal little specificity. This makes it necessary to consider the weights of connections between areas.

If the specificity of the cortical graph is derived from the weights of the connections between areas then one would predict that connection weight between two areas will be consistent across individuals. Few studies have attempted to characterise the inter-individual variability. One exception is a study by Scannell et al., (Scannell et al., 2000) who reported in collated data a 100 fold difference in the strength of a given corticocortical pathway across individuals. Because the differences in experimental procedure in different laboratories could largely contribute to variability observed by Scannel, we set out to make repeat injections in areas V1, V2 and V4 across individuals (Markov et al., 2011b). The results showed that connections formed by cortical neurons (i) are highly local, $80 \%$ of the connections are restricted to the cortical area and do not transverse more then $2-3 \mathrm{~mm}$; (ii) Of the $20 \%$ that project out of the injected area about two thirds are to the neighboring area. This leaves about $5 \%$ of the connections to form the extrinsic associative connectivity to be shared amongst the 25-50 cortical pathways that are formed by each cortical area. It is in the extrinsic pathways that we were able to show that weights spanned a considerable distance, over 5 units of $\log$, and that the weights were highly consistent across individuals (Falchier et al., 2002; Vezoli et al., 2004; Markov et al., 2011b). These results show that the connectivity profile of an individual cortical area is highly specific and that and it is the weight of the connections that will largely determine the specificity of the cortical graph. Further we were able to show that there is a weight distance relationship so that the nearest connections are the strongest and the weakest connections cover the greatest distance (Markov et al., 2011a; Markov et al., 2011b). While one can choose to ignore these weak long-distance connections it is important to note that they interconnect very different sorts of cortical areas and that their role in synchronisation could mean that they have important roles in long-distance coordination of brain activity. In a more philosophical vain one needs to remember the strength of weak connections in graph theory as a whole (Csermely, 2006).

\section{Neuron number specifies cortical hierarchy}

Much of our understanding of cortical function comes from the work in the visual cortex where the stimulus response function has been most extensively studied. Hubel and Wiesel's pioneering work showed that the receptive field structure of neurons in the visual cortex is progressively elaborated exhibiting simple, then complex and finally hypercomplex features. This observation leads these authors to postulate that cortex processes afferent information through a feedforward (FF) hierarchy of progressive abstract detectors (Hubel and Wiesel, 1968). Anatomical studies showed that FF pathways originate from SGL and terminate in layer 4, while feedback (FB) pathways originate from infragranular layers and terminate outside of layer 4 (Kennedy and Bullier, 1985). In the early 1990's David Van Essen's group showed that pair-wise comparison of these connections allowed the construction of a model of the cortex that captured many features including the dorsal and ventral streams of the visual cortices as well as a strict hierarchical organization which extended up to the prefrontal cortex (Felleman and Van Essen, 1991)(Fig 2a). Malcolm Young's group performed a statistical analysis of the Van Essen database and confirmed the basic features of the Van Essen hierarchy, including the ventral and dorsal streams. However, while the Young et al., organization appeared to be hierarchical they found that it was highly indeterminate, in fact they found over 150,000 equally plausible solutions to the hierarchy.

Indeterminacy in the Van Essen model stems from the fact that there is no indication of hierarchical distance between nodes coupled to the fact that there are numerous parallel pathways in addition to the dorsal and ventral streams. An anatomical solution to hierarchical distance is provided by the fact that long distance FF pathways arise uniquely from the SGL, and that as distance diminishes there is an increasingly important contribution to the projection from the infragranular layers (Fig 5). Likewise long distance FB projections originate uniquely from infragranular layers and as distance is reduced there are increasing contributions from SGL (Kennedy and Bullier, 1985; Dehay et al., 1986; Barone et al., 2000). Estimating the contributions of the SGL and infragranular layers to a given pathway involves quantitative estimations of numbers of neurons and defines the SLN\% (fraction of supragranular neurons) for a given pathway (SLN\%= number of SGL neurons/numbers of SGL + infragranular layer neurons). Accurate SLN values make it possible to construct a determinate model of the cortical hierarchy (Fig 5). 
A

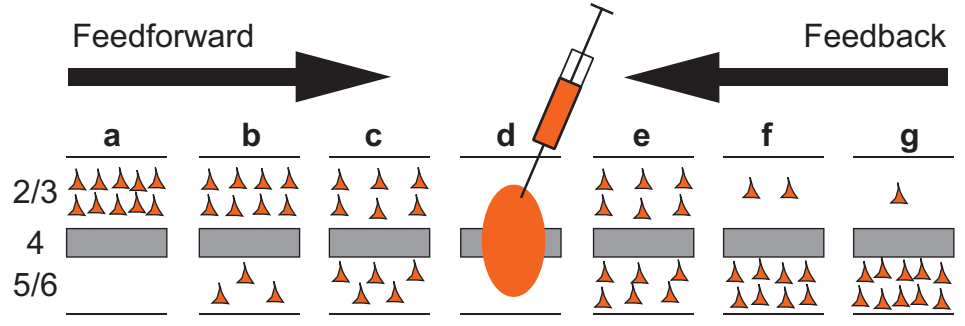

B

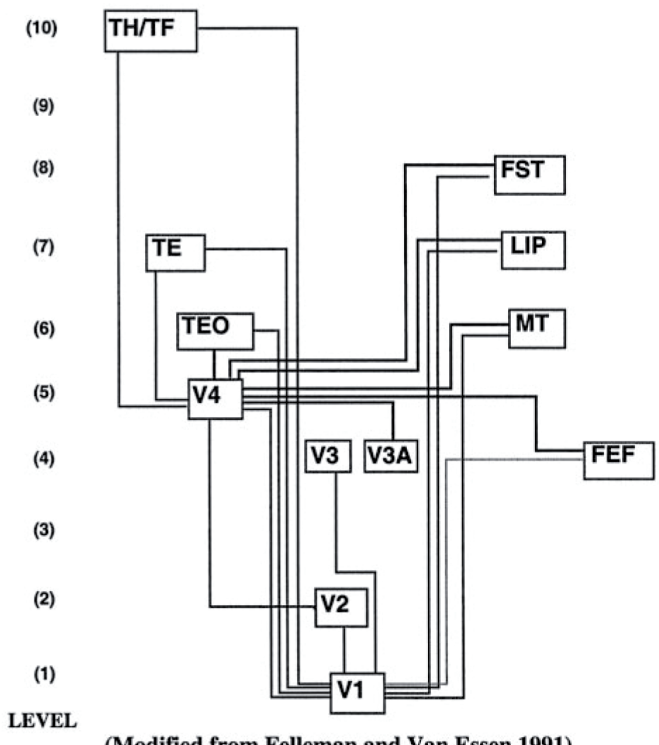

C

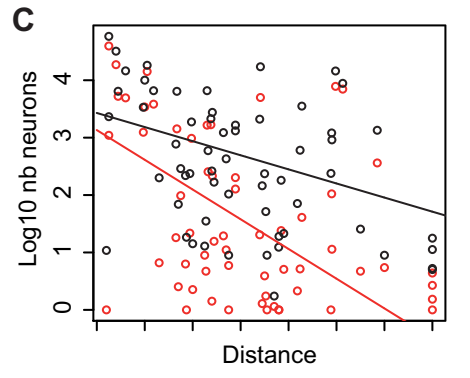

D

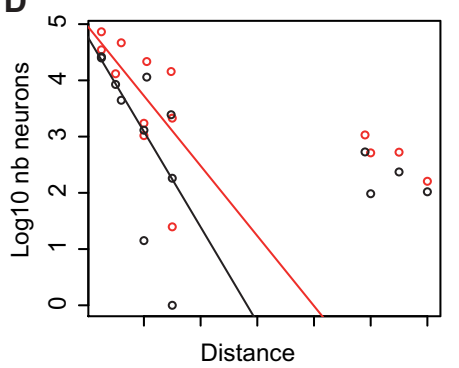

Figure 5. Laminar distribution and number of projection neurons determines hierarchy according to the operation of a distance rule. A: Cartoon illustrating the distribution of labelled neurons in feedforward and feedback projections after injection of a retrograde tracer in the target area. Each area exhibits a specific SLN value, which determines its hierarchical distance from the target area. Distant feedforward projections have SLN values of 100 (e.g. area a). More proximal areas have lower SLN values. Distant feedback projections have SLN values of 0 (e.g. area g). More proximal feedback areas have higher SLN values. SLN values of 40 to $60 \%$ correspond to lateral connections (areas c and e). B: Hierarchical model of cortical areas connected to the target area according to the relationship between the SLN\% and the distance rule (Barone et al., 2000). C: Feedback projections in the infragranular layers extend over long distances (blue circles) and over short distances in the supragranular layers (red circles). D: Feedforward projections in the supragranular layers extend over long distances (red circles) while feedforward projections in the infragranular layers extend over short distances (blue circles).

These findings show that the connectivity signature of a cortical area is defined by the individual strengths of 25 to 80 cortical areas that project to it, the hierarchical distance of each of these areas as reflected by its SLN and the numerical strength of the individual pathways. This would suggest that the physiological function of, or the range of information processing performed by the target area, is constrained by the particular profile of its inputs. Projections originating from SGL terminate in layer 4 and recurrent local circuits amplify the input signals before relaying them to the output neurons in the upper and lower layers (Douglas et al., 1995). The output of the cortex is modulated by the infragranular layer projections to layer 1 (Cauller, 1995) and to a lesser extent to layers 5 and 6 . In this way FF pathways construct the receptive field properties of the target and area while the FB pathways modulate the features of these receptive fields and the output of the target area.

What are the factors that set up the changes in SLN? One possibility is the way pathways in the cortex are highly dependent on distance. Elsewhere we have shown that there is an important exponential distance rule such that projections have low and neighboring projections high weights (Markov et al., 2011a). We have examined how the weights of labeled neurons in individual layers are influenced by distance. In feedback connections, the weight of layer 6 neurons falls off very much slower than do the weight of supragranular layers (Fig 5C), so that long distance feedback connections have low SLN values. Conversely, in feedforward pathways, the weights of infragranular layers fall off rapidly while those of supragranular layers fall rapidly so that long-distance feedforward pathways have high SLN values (fig 5D). These results show that the weight relations of a cortical area are globally constrained by an exponential distance rule, at a finer level a multiple distance rule acting independently on different layers establishes the hierarchical interareal relationships. 


\section{How does the cortex generate precise numbers of neurons?}

The coordinated regulation of two cardinal cell-cycle parameters of cortical precursors determines neuronal production via the regulation of the size of the precursor pool: the duration of the cell-cycle and the relative frequency of cell-cycle reentry compared with cell-cycle exit. In vivo and ex vivo analysis of the cellcycle regulation of OSVZ precursors of the primate visual cortex has shed light on the molecular correlates of area-specific differences in proliferation that underlie area-specific differences in the thickness of supragranular layers.

Compared to area $18 \mathrm{OSVZ}$ precursors, area $17 \mathrm{OSVZ}$ precursors are characterized by both a shorter cell-cycle duration, due to a reduction of the G1 phase, and an increased relative frequency of cell-cycle re-entry. These areal differences on OSVZ precursor cell-cycle regulation are associated with significant differences in the level of expression of molecular regulators of the G1/S transition p27kip1 and CyclinE. The ex-vivo up and down modulation of their level of expression significantly affects cell-cycle re-entry and the rate of cell-cycle progression and stresses the role of the G1 phase regulation in corticogenesis (Lukaszewicz et al., 2005; Lukaszewicz et al., 2006). Mathematical modeling of the observed differences in both rates of cell-cycle re-entry and in G1 phase duration show that the combined variation of these two parameters are sufficient to generate the enlarged SGL that distinguishes area 17 from area18. These result show that variations of G1 phase duration and the coordinated variation in mode of division contribute directly to regulate neuron number (Lukaszewicz et al., 2005).

In vitro work on mouse cortical precursors (Dehay et al., 2001) indicates that thalamic afferents control corticogenesis by modulating rates of proliferation. Embryonic thalamic axons release a mitogenic factor that increases the proliferative capacity of mouse cortical precursors during generation of SGL by decreasing the G1 duration and by promoting cell-cycle re-entry (Dehay et al., 2001). In the monkey, the LGN axons that selectively project onto the OSVZ of area 17 could be responsible for the temporally and spatially restricted stimulation of proliferation that results in the transient upsurge of the size of SGL precursor pool in area 17 (Dehay et al., 1993; Smart et al., 2002; Lukaszewicz et al., 2005). There are also in vivo indications in primates that embryonic thalamic axons could impact on areal size and specification via an early influence on neuron production during cortical neurogenesis (Dehay et al., 1989, 1991). Because thalamic axons are precisely targeted on to distinct cortical areas (reviewed in (Lopez-Bendito and Molnar, 2003) they will be able to differentially affect rates of precursor proliferation and of neuron production across the germinal zones and therefore determine local areal cytoarchitectonic features.

As we have shown above, the numerical values of the different projections neuron phenotypes determine the hierarchy and network features of the cortex. There is considerable evidence that the phenotypic fate is sealed during the final round of mitosis in the germinal zones and that the timing of this event is highly significant (Polleux et al., 2001; Chen et al., 2005a; Chen et al., 2005b; Molyneaux et al., 2005; Shen et al., 2006). It seems that fate specification is entirely premigratory as neurons that are destined for a given cortical layer and which end up in the inappropriate layer do not aquire the connectivity of the inappropriate layer (McConnell, 1988; Polleux et al., 2001).

The timing of the differentiative division that generates a given neuron type is not only directly involved in the specification but also in determining the number of neurons generated. Delaying the final differentiative division of a precursor pool, leads to increasing the number of proliferative divisions, which in turn leads to its amplification and hence expansion of the numbers of neurons generated (Polleux et al., 1997; Pilaz et al., 2009). Mathematical modelling of these events shows a high predictability of the numbers of neurons generated confirming the relationship between the kinetics of the cycling precursor and the cytoarchitecture of the cortex (Lukaszewicz et al., 2005; Pilaz et al., 2009).

There are numerous feedback loops in the neural epithelium that regulate the rate of proliferation in the germinal zones (Fig. 6). In the reeler mutant neuroblast migration is perturbed so that the last generated neurons end up deep in the cortex inverting the normal outside first inside last neurogenic gradient. Despite these changes in the laminar location of projection neurons the laminar and areal timetables are strictly conserved in this mutant. However this contrasts with the kinetics of the precursors and the determination of cell fate that are both highly perturbed confirming and extending previous findings of regulatory feedback loops from the cortical plate to the germinal zones (for a review see, Polleux et al., 1997). The other major regulatory pathways are between the OSVZ and the GZ as hypothesized above.

\section{Gain of function experiment exploring self-organization.}

The attractor or epigenetic landscape considers that the cell phenotype is defined in a state space in which the cell has a specific trajectory. This leads to phenotypic variability, which allows complex cellular interactions that underlie the emergence of biocomplexity. The peaks and saddles separating the valleys in the attractor 
landscape can be transverse, via forced gene expression. This we have explored in the above mentioned experiments where we have caused an acceleration of the cell cycle of cortical precursors during the production of SGL. This gain of function experiment led to an expansion of the mouse precursor pool resulting in an increased production of the SGL of the mouse. The increased size of the SVZ and the SGL of the mouse appears as a form of primatization of the rodent. Interestingly, with the expansion of the SVZ precursor pool there is also an important increase in the fraction of SVZ precursors that co-express Pax 6 and Tbr2. In mouse very few precursors co-express the two transcription factors while this is a characteristic feature of the macaque OSVZ.

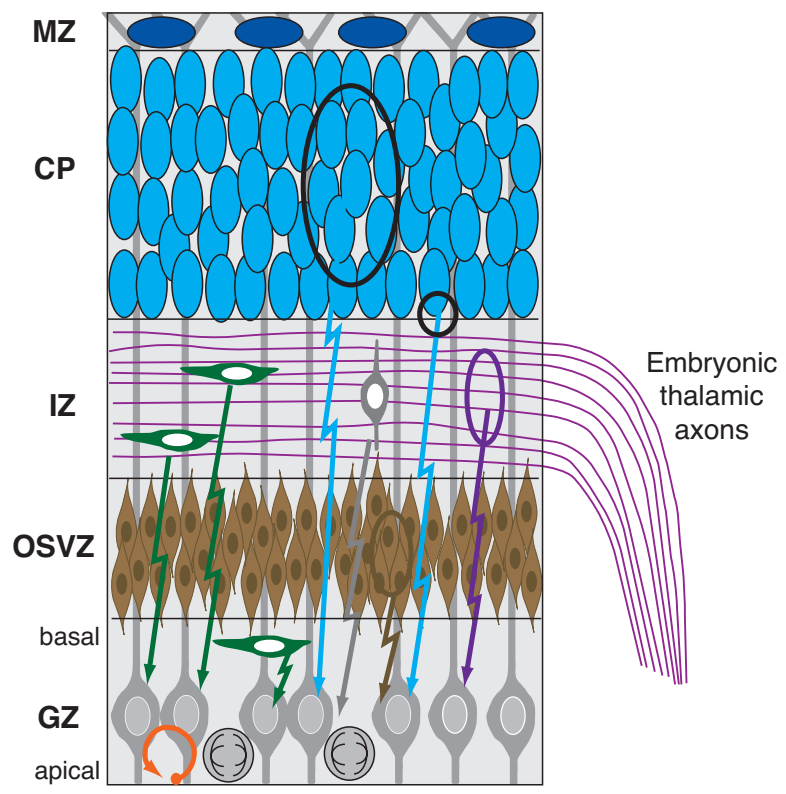

Figure 6. Schematic diagram of different extrinsic influences affecting precursor proliferation dynamics and cell fate. The different cellular compartments of the embryonic cortex are thought to provide signals that modulate the proliferation and fate of cortical precursors in germinal zones. Regulatory feedback includes influences from the postmitotic pyramidal neurons of the cortical plate (CP) (Polleux et al., 1998; Polleux et al., 2001) (blue cells), specifically from the lower layers (Viti et al., 2003) from newborn cortical neurons migrating in the intermediate zone (IZ) compartment (grey cell) and local feedback signalling from the germinal zone (GZ) precursors (circular arrow) (Lien et al., 2006). Extracortical extrinsic signals are provided by tangentially migrating interneurons generated in the ventral telencephalon (green cells) and by ingrowing embryonic thalamic axons (magenta) that have been shown to influence cell-cycle kinetics of precursors (Dehay et al., 2001). We hypothesize in the present report that IP precursors in the OSVZ send mitotic signals to the VZ. $\mathrm{MZ}$, marginal zone.

One can interprete these experimental results in terms of a modification of the normal regulatory control of mouse corticogeneis. One can hypothesize that the gain of function experiment described above is essentially revealing what would be the consequence of an increase in gain of thalamic regulation of corticogenesis, and that this could be mimicking what the expansion of cortex during evolution. Earlier studies have shown that thalamic afferents release a mitogen that shortens the cell cycle via reduction of the G1 phase, leading to an increase in cell cycle reentry and an increase in the precursor pool (Dehay et al., 2001). This conclusion is in accordance with the demonstration that removal of thalamic fibers has little effect on rodent development and an important effect in prenatal monkey development (Rakic, 1988; Dehay et al., 1989, 1991; Dehay et al., 1996). The finding that interests us here is that the experimental gain of function experiment resulting from cell cycle acceleration induces the expression of Pax 6 in precursors that would normally be uniquely expressing Tbr2. Understanding this experimental result in the framework of the Kauffman hypothesis, suggests what has happened is that there is a modification of the attractor landscape of the mouse cortical precursor via the G1 reduction, that mimics what is happening during normal development under the influence of the thalamic control of corticogenesis, suggesting that the regulatory loops are shaping the attractor landscape of the cortical precursor cells via modification of the gene regulatory network (Kauffman, 1993). These results explores the idea that selforganization of the brain is tightly linked to it's evolution involves cell-cell interactions with far reaching consequences and where phenotypic variability plays a crucial role.

\section{Conclusion}

A recent study in Nature explored experimentally the concept of self-organization. The group of Yoshiki Sasai showed that a homogeneous population of embryonic-stem-cell derived neural epithelium spontaneously underwent optic-cup morphogenesis in 3-D culture (Eiraku et al., 2011). These authors were able to report the spontaneous formation of epithelial vesicles patterned along their proximal-distal axis, exhibiting interkinetic 
nuclear migration and generating a stratified neural retinal tissue following the steps of normal development in vivo. According to our definition of self-organization in the Introduction, we would predict that there is an oscillatory state in the homogeneous pool of stem cells, possibly here involving wnt signaling, that underwent spatial temporal modulation to drive the cell population to form optic vesicles in vitro. If future regenerative medicines protocols are going to follow this strategy they will aim to control the identity of the initial oscillatory state so as to obtain the desired organ. While this research heralds enormous potential for regenerative medicine it also tells us something very deep about normal development. The fact that a simple cell culture system can undergo intrinsic self-organization to generate a complex structure without external cues emphasizes the importance that self-organization has in the normal developmental process.

The brain is a remarkable computational system. Unlike conventional computers it does not rely on an external agency for its construction and programming. Instead, the entire circuitry is self-constructed by replication and interaction of the germinal cells and their derived neuronal types. Unlike the majority of tissues that emphasize local three-dimensional organization where cells contact their neighbors, the CNS is characterized by complex connectional topologies over very large spatial scales. The underlying need for this organization is due to the fact that information processing is finally about selective communication between particular processors. Such functions can be represented as a graph-like topology composed of processing nodes (single or populations of neurons), and their connecting communication edges (axons).

\section{Acknowledgements}

This work was supported by FP6-2005 IST-1583 (HK); FP7-2007 ICT-216593 (HK-CD); ANR-05NEUR-088 (HK); ANR-06-NEUR-CMMCS (CD). We thank Nikola Markov and who made important contributions to understanding the role of a distance rules in determining cortical hierarchy and Kenneth Knoblauch for teaching us the importance of count data for understanding structure.

\section{References}

Arai, Y., Pulvers, J. N., Haffner, C., Schilling, B., Nusslein, I., Calegari, F. \& Huttner, W. B. (2011). Neural stem and progenitor cells shorten S-phase on commitment to neuron production. Nature Communications, 2, 154.

Arlotta, P., Molyneaux, B. J., Chen, J., Inoue, J., Kominami, R. \& Macklis, J. D. (2005). Neuronal subtypespecific genes that control corticospinal motor neuron development in vivo. Neuron, 45, 207-221.

Barone, P., Batardiere, A., Knoblauch, K. \& Kennedy, H. (2000). Laminar distribution of neurons in extrastriate areas projecting to visual areas V1 and V4 correlates with the hierarchical rank and indicates the operation of a distance rule. The Journal of Neuroscience, 20, 3263-3281.

Barone, P., Dehay, C., Berland, M., Bullier, J. \& Kennedy, H. (1995). Developmental remodeling of primate visual cortical pathways. Cerebral Cortex, 5, 22-38.

Barone, P., Dehay, C., Berland, M. \& Kennedy, H. (1996). Role of directed growth and target selection in the formation of cortical pathways: prenatal development of the projection of area V2 to area V4 in the monkey. Journal of Comparative Neurology, 374, 1-20.

Bedford, L., Walker, R., Kondo, T., van Cruchten, I., King, E. R. \& Sablitzky, F. (2005). Id4 is required for the correct timing of neural differentiation. Developmental Biology, 280, 386-395.

Berkes, P., Orban, G., Lengyel, M. \& Fiser, J. (2011). Spontaneous cortical activity reveals hallmarks of an optimal internal model of the environment. Science, 331, 83-87.

Brazhnik, P., de la Fuente, A. \& Mendes, P. (2002). Gene networks: how to put the function in genomics. Trends in Biotechnology, 20, 467-472.

Britanova, O., Akopov, S., Lukyanov, S., Gruss, P. \& Tarabykin, V. (2005). Novel transcription factor Satb2 interacts with matrix attachment region DNA elements in a tissue-specific manner and demonstrates celltype-dependent expression in the developing mouse CNS. The European Journal of Neuroscience, 21, 658668.

Calegari, F. \& Huttner, W. B. (2003). An inhibition of cyclin-dependent kinases that lengthens, but does not arrest, neuroepithelial cell cycle induces premature neurogenesis. Journal of Cell Science, 116, 4947-4955.

Cappello, S., Attardo, A., Wu, X., Iwasato, T., Itohara, S., Wilsch-Brauninger, M., Eilken, H. M., Rieger, M. A., Schroeder, T. T., Huttner, W. B., Brakebusch, C. \& Gotz, M. (2006). The Rho-GTPase cdc42 regulates neural progenitor fate at the apical surface. Nature Neuroscience, 9, 1099-1107.

Cauller, L. (1995). Layer I of primary sensory neocortex: where top-down converges upon bottom-up. Behavioural Brain Research, 71, 163-170.

Chang, H. H., Hemberg, M., Barahona, M., Ingber, D. E. \& Huang, S. (2008). Transcriptome-wide noise controls lineage choice in mammalian progenitor cells. Nature, 453, 544-547. 
Chen, B., Schaevitz, L. R. \& McConnell, S. K. (2005a). Fezl regulates the differentiation and axon targeting of layer 5 subcortical projection neurons in cerebral cortex. Proceedings of the National Academy of Sciences of the United States of America, 102, 17184-17189.

Chen, J. G., Rasin, M. R., Kwan, K. Y. \& Sestan, N. (2005b). Zfp312 is required for subcortical axonal projections and dendritic morphology of deep-layer pyramidal neurons of the cerebral cortex. Proceedings of the National Academy of Sciences of the United States of America, 102, 17792-17797.

Chen, L., Liao, G., Yang, L., Campbell, K., Nakafuku, M., Kuan, C. Y. \& Zheng, Y. (2006). Cdc42 deficiency causes Sonic hedgehog-independent holoprosencephaly. Proceedings of the National Academy of Sciences of the United States of America, 103, 16520-16525.

Chenn, A. \& Walsh, C. A. (2002). Regulation of cerebral cortical size by control of cell cycle exit in neural precursors. Science, 297, 365-369.

Cheung, A. F., Pollen, A. A., Tavare, A., DeProto, J. \& Molnar, Z. (2007). Comparative aspects of cortical neurogenesis in vertebrates. Journal of Anatomy, 211, 164-176.

Csermely, P. (2006) Weak Links: Stabilizers of complex systems from protein to social networks. Springer: Berlin.

Dehay, C., Giroud, P., Berland, M., Killackey, H. \& Kennedy, H. (1996). Contribution of thalamic input to the specification of cytoarchitectonic cortical fields in the primate: effects of bilateral enucleation in the fetal monkey on the boundaries, dimensions, and gyrification of striate and extrastriate cortex. Journal of Comparative Neurology, 367, 70-89.

Dehay, C., Giroud, P., Berland, M., Smart, I. \& Kennedy, H. (1993). Modulation of the cell cycle contributes to the parcellation of the primate visual cortex. Nature, 366, 464-466.

Dehay, C., Horsburgh, G., Berland, M., Killackey, H. \& Kennedy, H. (1989). Maturation and connectivity of the visual cortex in monkey is altered by prenatal removal of retinal input. Nature, 337, 265-267.

Dehay, C., Horsburgh, G., Berland, M., Killackey, H. \& Kennedy, H. (1991). The effects of bilateral enucleation in the primate fetus on the parcellation of visual cortex. Developmental Brain Research, 62, 137-141.

Dehay, C. \& Kennedy, H. (2007). Cell-cycle control and cortical development. Nature Reviews Neuroscience, 8, 438-450.

Dehay, C., Kennedy, H. \& Bullier, J. (1986). Callosal connectivity of areas V1 and V2 in the newborn monkey. Journal of Comparative Neurology, 254, 20-33.

Dehay, C., Savatier, P., Cortay, V. \& Kennedy, H. (2001). Cell-cycle kinetics of neocortical precursors are influenced by embryonic thalamic axons. The Journal of Neuroscience, 21, 201-214.

Douglas, R. J., Koch, C., Mahowald, M., Martin, K. A. \& Suarez, H. H. (1995). Recurrent excitation in neocortical circuits. Science, 269, 981-985.

Eiraku, M., Takata, N., Ishibashi, H., Kawada, M., Sakakura, E., Okuda, S., Sekiguchi, K., Adachi, T. \& Sasai, Y. (2011). Self-organizing optic-cup morphogenesis in three-dimensional culture. Nature, 472, 51-56.

Falchier, A., Clavagnier, S., Barone, P. \& Kennedy, H. (2002). Anatomical evidence of multimodal integration in primate striate cortex. The Journal of Neuroscience, 22, 5749-5759.

Felleman, D. J. \& Van Essen, D. C. (1991). Distributed hierarchical processing in the primate cerebral cortex. Cerebral Cortex, 1, 1-47.

Fietz, S. A., Kelava, I., Vogt, J., Wilsch-Brauninger, M., Stenzel, D., Fish, J. L., et al. (2010). OSVZ progenitors of human and ferret neocortex are epithelial-like and expand by integrin signaling. Nature Neuroscience, 13, 690-699.

Fish, J. L., Dehay, C., Kennedy, H. \& Huttner, W. B. (2008). Making bigger brains-the evolution of neuralprogenitor-cell division. Journal of Cell Science, 121, 2783-2793.

Frantz, G. D., Weimann, J. M., Levin, M. E. \& McConnell, S. K. (1994). Otx1 and Otx2 define layers and regions in developing cerebral cortex and cerebellum. The Journal of Neuroscience, 14, 5725-5740.

Gal, J. S., Morozov, Y. M., Ayoub, A. E., Chatterjee, M., Rakic, P. \& Haydar, T. F. (2006). Molecular and morphological heterogeneity of neural precursors in the mouse neocortical proliferative zones. The Journal of Neuroscience, 26, 1045-1056.

Geisler, W. S. \& Diehl, R. L. (2002). Bayesian natural selection and the evolution of perceptual systems. Philosophical Transactions of the Royal Society B: Biological Sciences, 357, 419-448.

Gotz, M. \& Huttner, W. B. (2005). The cell biology of neurogenesis. Nature Reviews Molecular Cell Biology, 6, 777-788.

Götz, M., Stoykova, A. \& Gruss, P. (1998). Pax6 controls radial glia differentiation in teh cerebral cortex. Neuron, 21, 1031-1044.

Halley, J. D. \& Winkler, D. A. (2008a). Consistent concepts of self-organization and self-assembly. Complexity, $14,10-17$.

Halley, J. D. \& Winkler, D. A. (2008b). Critical-like self-organization and natural selection: two facets of a single evolutionary process? Biosystems, 92, 148-158. 
Hansen, D. V., Lui, J. H., Parker, P. R., \& Kriegstein, A. R. (2010). Neurogenic radial glia in the outer subventricular zone of human neocortex. Nature, 464, 554-561.Hartfuss, E., Galli, R., Heins, N. \& Gotz, M. (2001). Characterization of CNS precursor subtypes and radial glia. Developmental Biology, 229, 15-30.

Haubensak, W., Attardo, A., Denk, W. \& Huttner, W. B. (2004). Neurons arise in the basal neuroepithelium of the early mammalian telencephalon: a major site of neurogenesis. Proceedings of the National Academy of Sciences of the United States of America, 101, 3196-3201.

Heins, N., Malatesta, P., Cecconi, F., Nakafuku, M., Tucker, K. L., Hack, M. A., Chapouton, P., Barde, Y. A. \& Gotz, M. (2002). Glial cells generate neurons: the role of the transcription factor Pax6. Nature Neuroscience, 5, 308-315.

Hevner, R. F. (2005). The cerebral cortex malformation in thanatophoric dysplasia: neuropathology and pathogenesis. Acta Neuropathologica, 110, 208-221.

Hill, R. S., \& Walsh, C. A. (2005) Molecular insights into human brain evolution. Nature, 437, 64-67.Holm, P. C., Mader, M. T., Haubst, N., Wizenmann, A., Sigvardsson, M. \& Gotz, M. (2007). Loss- and gain-offunction analyses reveal targets of Pax6 in the developing mouse telencephalon. Molecular and Cellular Neuroscience, 34, 99-119.

Honey, C. J., Kotter, R., Breakspear, M. \& Sporns, O. (2007). Network structure of cerebral cortex shapes functional connectivity on multiple time scales. Proceedings of the National Academy of Sciences of the United States of America, 104, 10240-10245.

Huang, S. (2009). Non-genetic heterogeneity of cells in development: more than just noise. Development, 136, 3853-3862.

Hubel, D. H. \& Wiesel, T. N. (1968). Receptive fields and functional architecture of monkey striate cortex. Journal of Physiology, 195, 215-243.

Inglis-Broadgate, S. L., Thomson, R. E., Pellicano, F., Tartaglia, M. A., Pontikis, C. C., Cooper, J. D. \& Iwata, T. (2005). FGFR3 regulates brain size by controlling progenitor cell proliferation and apoptosis during embryonic development. Developmental Biology, 279, 73-85.

Jouve, B., Rosenstiehl, P. \& Imbert, M. (1998). A mathematical approach to the connectivity between the cortical visual areas of the macaque monkey. Cerebral Cortex, 8, 28-39.

Kauffman, S. A. (1993) The origins of order. Oxford University Press: New York - Oxford.

Kauffman, S. A. (2000) Investigations. Oxford University Press: New York.

Kennedy, H. \& Bullier, J. (1985). A double-labeling investigation of the afferent connectivity to cortical areas V1 and V2 of the macaque monkey. The Journal of Neuroscience, 5, 2815-2830.

Kennedy, H., Bullier, J. \& Dehay, C. (1989). Transient projections from the superior temporal sulcus to area 17 in the newborn macaque monkey. Proceedings of the National Academy of Sciences of the United States of America, 86, 8093-8097.

Kennedy, H. \& Dehay, C. (1993). Cortical specification of mice and men. Cerebral Cortex, 3, 27-35.

Kennedy, H. \& Orban, G. A. (1983). Response properties of visual cortical neurons in cats reared in stroboscopic illumination. Journal of Neurophysiology, 49, 686-704.

Killackey, H. P. (1990). Neocortical expansion: an attempt towards relating phylogeny and ontogeny. Journal of Cognitive Neuroscience, 2, 1-17.

Kowalczyk, T., Pontious, A., Englund, C., Daza, R. A., Bedogni, F., Hodge, R., Attardo, A., Bell, C., Huttner, W. B. \& Hevner, R. F. (2009). Intermediate neuronal progenitors (basal progenitors) produce pyramidalprojection neurons for all layers of cerebral cortex. Cerebral Cortex, 19, 2439-2450.

Kriegstein, A., Noctor, S. \& Martinez-Cerdeno, V. (2006). Patterns of neural stem and progenitor cell division may underlie evolutionary cortical expansion. Nature Reviews Neuroscience, 7, 883-890.

Kuida, K., Haydar, T. F., Kuan, C. Y., Gu, Y., Taya, C., Karasuyama, H., Su, M. S., Rakic, P. \& Flavell, R. A. (1998). Reduced apoptosis and cytochrome c-mediated caspase activation in mice lacking caspase 9. Cell, 94, 325-337.

Land, P. W. \& Monaghan, A. P. (2003). Expression of the transcription factor, tailless, is required for formation of superficial cortical layers. Cerebral Cortex, 13, 921-931.

Lange, C., Huttner, W. B. \& Calegari, F. (2009). Cdk4/cyclinD1 overexpression in neural stem cells shortens G1, delays neurogenesis, and promotes the generation and expansion of basal progenitors. Cell Stem Cell, 5, 320-331.

LeVay, S., Wiesel, T. N. \& Hubel, D. H. (1980). The development of ocular dominance columns in normal and visually deprived monkeys. Journal of Comparative Neurology, 191, 1-51.

Levitt, P., Cooper, M. L. \& Rakic, P. (1981). Coexistence of neuronal and glial precursor cells in the cerebral ventricular zone of the fetal monkey: an ultrastructural immunoperoxidase analysis. The Journal of Neuroscience, 1, 27-39.

Lien, W. H., Klezovitch, O., Fernandez, T. E., Delrow, J. \& Vasioukhin, V. (2006). alphaE-catenin controls cerebral cortical size by regulating the hedgehog signaling pathway. Science, 311, 1609-1612. 
Lopez-Bendito, G. \& Molnar, Z. (2003). Thalamocortical development: how are we going to get there? Nature Reviews Neuroscience, 4, 276-289.

Lukaszewicz, A., Cortay, V., Giroud, P., Berland, M., Smart, I., Kennedy, H. \& Dehay, C. (2006). The concerted modulation of proliferation and migration contributes to the specification of the cytoarchitecture and dimensions of cortical areas. Cerebral Cortex, 16 Suppl 1, i26-34.

Lukaszewicz, A., Savatier, P., Cortay, V., Giroud, P., Huissoud, C., Berland, M., Kennedy, H. \& Dehay, C. (2005). G1 phase regulation, area-specific cell cycle control, and cytoarchitectonics in the primate cortex. Neuron, 47, 353-364.

Lukaszewicz, A., Savatier, P., Cortay, V., Kennedy, H. \& Dehay, C. (2002). Contrasting effects of basic fibroblast growth factor and neurotrophin 3 on cell cycle kinetics of mouse cortical stem cells. The Journal of Neuroscience, 22, 6610-6622.

Malatesta, P., Hack, M. A., Hartfuss, E., Kettenmann, H., Klinkert, W., Kirchhoff, F. \& Gotz, M. (2003). Neuronal or glial progeny: regional differences in radial glia fate. Neuron, 37, 751-764.

Malatesta, P., Hartfuss, E. \& Gotz, M. (2000). Isolation of radial glial cells by fluorescent-activated cell sorting reveals a neuronal lineage. Development, 127, 5253-5263.

Markov, N. T., Ercsey-Ravasz, M. M., Gariel, M. A., Dehay, C., Knoblauch, A., Toroczkai, Z. \& Kennedy, H. (2011a). The tribal networks of the cerebral cortex. In L. M. Chalupa, N. Berardi, M. Caleo, L. Galli-Resta \& T. Pizzorusso (Eds.), Cerebral Plasticity (pp. 275-290). MIT Press: Cambridge MA.

Markov, N. T., Misery, P., Falchier, A., Lamy, C., Vezoli, J., Quilodran, R., Gariel, M. A., Giroud, P., ErcseyRavasz, M., Pilaz, L. J., Huissoud, C., Barone, P., Dehay, C., Toroczkai, Z., Van Essen, D. C., Kennedy, H. \& Knoblauch, K. (2011b). Weight Consistency Specifies Regularities of Macaque Cortical Networks. Cerebral Cortex, 21, 1254-1272.

Martinez-Cerdeno, V., Noctor, S. C. \& Kriegstein, A. R. (2006). The role of intermediate progenitor cells in the evolutionary expansion of the cerebral cortex. Cerebral Cortex, 16 Suppl 1, i152-161.

McConnell, S. K. (1988). Fates of visual cortical neurons in the ferret after isochronic and heterochronic transplantation. The Journal of Neuroscience, 8, 945-974.

Miyata, T., Kawaguchi, A., Saito, K., Kawano, M., Muto, T. \& Ogawa, M. (2004). Asymmetric production of surface-dividing and non-surface-dividing cortical progenitor cells. Development, 131, 3133-3145.

Molnar, Z., Metin, C., Stoykova, A., Tarabykin, V., Price, D. J., Francis, F., Meyer, G., Dehay, C. \& Kennedy, H. (2006). Comparative aspects of cerebral cortical development. The European Journal of Neuroscience, 23 , 921-934.

Molyneaux, B. J., Arlotta, P., Hirata, T., Hibi, M. \& Macklis, J. D. (2005). Fezl is required for the birth and specification of corticospinal motor neurons. Neuron, 47, 817-831.

Nieto, M., Monuki, E. S., Tang, H., Imitola, J., Haubst, N., Khoury, S. J., Cunningham, J., Gotz, M. \& Walsh, C. A. (2004). Expression of Cux-1 and Cux-2 in the subventricular zone and upper layers II-IV of the cerebral cortex. Journal of Comparative Neurology, 479, 168.

Noctor, S. C., Flint, A. C., Weissman, T. A., Dammerman, R. S. \& Kriegstein, A. R. (2001). Neurons derived from radial glial cells establish radial units in neocortex. Nature, 409, 714-720.

Noctor, S. C., Flint, A. C., Weissman, T. A., Wong, W. S., Clinton, B. K. \& Kriegstein, A. R. (2002). Dividing precursor cells of the embryonic cortical ventricular zone have morphological and molecular characteristics of radial glia. The Journal of Neuroscience, 22, 3161-3173.

Noctor, S. C., Martinez-Cerdeno, V., Ivic, L. \& Kriegstein, A. R. (2004). Cortical neurons arise in symmetric and asymmetric division zones and migrate through specific phases. Nature Neuroscience, 7, 136-144.

O'Leary, D. D. M. (1989). Do cortical areas emerge from a protocortex? Trends in Neurosciences, 12, 400-406.

Pilaz, L. J., Patti, D., Marcy, G., Ollier, E., Pfister, S., Douglas, R. J., Betizeau, M., Gautier, E., Cortay, V., Doerflinger, N., Kennedy, H. \& Dehay, C. (2009). Forced G1-phase reduction alters mode of division, neuron number, and laminar phenotype in the cerebral cortex. Proceedings of the National Academy of Sciences of the United States of America, 106, 21924-21929.

Pinto, L., Drechsel, D., Schmid, M. T., Ninkovic, J., Irmler, M., Brill, M. S., Restani, L., Gianfranceschi, L., Cerri, C., Weber, S. N., Tarabykin, V., Baer, K., Guillemot, F., Beckers, J., Zecevic, N., Dehay, C., Caleo, M., Schorle, H. \& Gotz, M. (2009). AP2gamma regulates basal progenitor fate in a region- and layer-specific manner in the developing cortex. Nature Neuroscience, 12, 1229-1237.

Polleux, F., Dehay, C., Goffinet, A. \& Kennedy, H. (2001). Pre- and post-mitotic events contribute to the progressive acquisition of area-specific connectional fate in the neocortex. Cerebral Cortex, 11, 1027-1039.

Polleux, F., Dehay, C. \& Kennedy, H. (1998). Neurogenesis and commitment of corticospinal neurons in reeler. The Journal of Neuroscience, 18, 9910-9923.

Polleux, F., Dehay, C., Moraillon, B. \& Kennedy, H. (1997). Regulation of neuroblast cell-cycle kinetics plays a crucial role in the generation of unique features of neocortical areas. The Journal of Neuroscience, 17, 77637783. 
Pontious, A., Kowalczyk, T., Englund, C. \& Hevner, R. F. (2008). Role of intermediate progenitor cells in cerebral cortex development. Developmental Neuroscience, 30, 24-32.

Quinn, J. C., Molinek, M., Martynoga, B. S., Zaki, P. A., Faedo, A., Bulfone, A., Hevner, R. F., West, J. D. \& Price, D. J. (2007). Pax6 controls cerebral cortical cell number by regulating exit from the cell cycle and specifies cortical cell identity by a cell autonomous mechanism. Developmental Biology, 302, 50-65.

Rakic, P. (1988). Defects of neuronal migration and the pathogenesis of cortical malformations. Progress in Brain Research, 73, 15-37.

Rakic, P. (2003). Developmental and evolutionary adaptations of cortical radial glia. Cerebral Cortex, 13, 541549.

Reznikov, K., Acklin, S. E. \& van der Kooy, D. (1997). Clonal heterogeneity in the early embryonic rodent cortical germinal zone and the separation of subventricular from ventricular zone lineages. Developmental Dynamics, 210, 328-343.

Roy, K., Kuznicki, K., Wu, Q., Sun, Z., Bock, D., Schutz, G., Vranich, N. \& Monaghan, A. P. (2004). The Tlx gene regulates the timing of neurogenesis in the cortex. The Journal of Neuroscience, 24, 8333-8345.

Scannell, J. W., Grant, S., Payne, B. R. \& Baddeley, R. (2000). On variability in the density of corticocortical and thalamocortical connections. Philosophical Transactions of the Royal Society B: Biological Sciences, $355,21-35$.

Schmechel, D. E. \& Rakic, P. (1979). Arrested proliferation of radial glial cells during midgestation in rhesus monkey. Nature, 277, 303-305.

Schuurmans, C., Armant, O., Nieto, M., Stenman, J. M., Britz, O., Klenin, N., Brown, C., Langevin, L. M., Seibt, J., Tang, H., Cunningham, J. M., Dyck, R., Walsh, C., Campbell, K., Polleux, F. \& Guillemot, F. (2004). Sequential phases of cortical specification involve Neurogenin-dependent and -independent pathways. The EMBO Journal, 23, 2892-2902.

Shen, Q., Wang, Y., Dimos, J. T., Fasano, C. A., Phoenix, T. N., Lemischka, I. R., Ivanova, N. B., Stifani, S., Morrisey, E. E. \& Temple, S. (2006). The timing of cortical neurogenesis is encoded within lineages of individual progenitor cells. Nature Neuroscience, 9, 743-751.

Shepard, R. N. (2001). Perceptual-cognitive universals as reflections of the world. The Behavioral and Brain Sciences, 24, 581-601; discussion 652-571.

Smart, I. H., Dehay, C., Giroud, P., Berland, M. \& Kennedy, H. (2002). Unique morphological features of the proliferative zones and postmitotic compartments of the neural epithelium giving rise to striate and extrastriate cortex in the monkey. Cerebral Cortex, 12, 37-53.

Smart, I. H. M. (1973). Proliferative characteristics of the ependymal layer during the early development of the mouse neocortex: a pilot study based on recording the number, location and plane of cleavage of mitotic figures. Journal of Anatomy, 116, 67-91.

Sporns, O. (2011) Networks of the brain. MIT Press: Cambridge, Mass.

Sur, M. \& Rubenstein, J. L. (2005). Patterning and plasticity of the cerebral cortex. Science, 310, 805-810.

Tarabykin, V., Stoykova, A., Usman, N. \& Gruss, P. (2001). Cortical upper layer neurons derive from the subventricular zone as indicated by Svetl gene expression. Development, 128, 1983-1993.

Thompson, I. D., Kossut, M. \& Blakemore, C. (1983). Development of orientation columns in cat striate cortex revealed by 2-deoxyglucose autoradiography. Nature, 301, 712-715.

Van der Loos, H. (1977). Structural changes in the cerebral cortex upon modification of the periphery: barrels in somatosensory cortex. Philosophical Transactions of the Royal Society B: Biological Sciences, 278, 373-376.

van Ooyen, A. (2011). Using theoretical models to analyse neural development. Nature Reviews Neuroscience, 12, 311-326.

Vezoli, J., Falchier, A., Jouve, B., Knoblauch, K., Young, M. \& Kennedy, H. (2004). Quantitative analysis of connectivity in the visual cortex: extracting function from structure. The Neuroscientist, 10, 476-482.

Viti, J., Gulacsi, A. \& Lillien, L. (2003). Wnt regulation of progenitor maturation in the cortex depends on Shh or fibroblast growth factor 2. The Journal of Neuroscience, 23, 5919-5927.

Wu, S. X., Goebbels, S., Nakamura, K., Nakamura, K., Kometani, K., Minato, N., Kaneko, T., Nave, K. A. \& Tamamaki, N. (2005). Pyramidal neurons of upper cortical layers generated by NEX-positive progenitor cells in the subventricular zone. Proceedings of the National Academy of Sciences of the United States of America, $102,17172-17177$.

Young, M. P. (1992). Objective analysis of the topological organization of the primate cortical visual system. Nature, 358, 152-155.

Yun, K., Mantani, A., Garel, S., Rubenstein, J. \& Israel, M. A. (2004). Id4 regulates neural progenitor proliferation and differentiation in vivo. Development, 131, 5441-5448.

Zecevic, N., Chen, Y. \& Filipovic, R. (2005). Contributions of cortical subventricular zone to the development of the human cerebral cortex. Journal of Comparative Neurology, 491, 109-122. 
Zhou, C. J., Borello, U., Rubenstein, J. L. \& Pleasure, S. J. (2006). Neuronal production and precursor proliferation defects in the neocortex of mice with loss of function in the canonical Wnt signaling pathway. Neuroscience, 142, 1119-1131.

Zimmer, C., Tiveron, M. C., Bodmer, R. \& Cremer, H. (2004). Dynamics of Cux2 Expression Suggests that an Early Pool of SVZ Precursors is Fated to Become Upper Cortical Layer Neurons. Cerebral Cortex, 14, 14081420 .

Zubler, F. \& Douglas, R. (2009). A framework for modeling the growth and development of neurons and networks. Frontiers in Computational Neuroscience, 3, 25. 